\title{
Dissipative Bracing-Based Seismic Retrofit of R/C School Buildings
}

\author{
Stefano Sorace ${ }^{*}, 1$ and Gloria Terenzi ${ }^{2}$
}

\author{
${ }^{I}$ Department of Civil Engineering and Architecture, University of Udine, via delle Scienze 208 - 33100 Udine, Italy; \\ ${ }^{2}$ Department of Civil and Environmental Engineering, University of Florence, Via S. Marta 3 - 50139 Florence, Italy
}

\begin{abstract}
A dissipative bracing system incorporating pressurized fluid viscous spring-dampers has been studied for many years by the authors as an alternative seismic protection strategy for new and existing frame structures. As a concluding stage of this activity, a set of demonstrative case studies was examined to illustrate the enhancement of seismic performance and the economic advantages guaranteed by the system in actual design applications. The paper offers a selection of two among these case studies, both concerning retrofit interventions of reinforced concrete school buildings designed with earlier Seismic Standards editions, representative of a large stock of similar edifices built during the 1970s and earlier 1980s. The following aspects are presented and discussed in detail: the mechanical parameters, layouts and locations selected for the constituting elements of the system; the architectural refurbishment projects developed to properly incorporate the structural interventions and improve the appearance of the buildings; highlights of the installation works completed in one of the two case studies; and a synthesis of the performance assessment analyses in original and rehabilitated conditions, developed according to a full non-linear dynamic approach. The results of the analyses show a remarkable enhancement of the seismic response capacities of both structures. This allows reaching the high performance objectives postulated in the retrofit designs, with much lower costs and architectural intrusion as compared to traditional rehabilitation interventions designed for the same objectives.
\end{abstract}

Keywords: Seismic retrofit, seismic assessment, existing R/C structures, school buildings, dissipative braces, fluid viscous dampers.

\section{INTRODUCTION}

A wide stock of public edifices with reinforced concrete $(\mathrm{R} / \mathrm{C})$ frame structure was designed during the 1970s and early 1980s in Italy under the first editions of the reference Seismic Standards, characterized by a traditional strengthbased conception. As a consequence, the performance capacities of these buildings (including schools, hospitals, administrative headquarters, office and commercial departments, etc.) fall below the basic levels required by the latest Standards editions, especially in terms of member ductility and total displacement/interstory drift control. At the same time, the mechanical properties of concrete and steel, the quality of reinforcing elements, and the ultimate resistance of members, foundations included, are not so poor as to impose the demolition and rebuilding of these structures. This suggests that their seismic retrofit is the preferable action strategy to be adopted. To this aim, attention is particularly paid to supplemental damping-based rehabilitation technologies, which are capable of guaranteeing the highest performance with the lowest architectural impact and structural intrusion, as well as a short interruption in the use of the buildings, and lower costs as compared to traditional retrofit solutions [1-22].

Among these technologies, a special dissipative bracing (DB) system incorporating pressurized fluid viscous (FV) spring-dampers as protective devices, proved to be a very effective and economically viable retrofit strategy for R/C as

\footnotetext{
* Address correspondence to this author at the Department of Civil Engineering and Architecture, University of Udine, via delle Scienze 208 33100 Udine (Italy); Tel: 0039-432-558050; Fax: 0039-432-558052;

E-mails: stefano.sorace@uniud.it; terenzi@dicea.unifi.it
}

well as steel frame structures $[7,9,10,13,14,21,22]$. Extensive pseudodynamic $[9,10,13]$ and shaking table [22] experimental campaigns on large and full-scale structures supported the technical implementation of the system and validated the analytical/numerical models and design procedures developed for its analysis and sizing.

Two R/C Italian school buildings, well representative of the characteristics of this early-Standards-designed stock of public edifices discussed above, are examined in this paper as demonstrative case study applications of the DB technology. The first building, situated in the province of Cosenza, Calabria region, was assumed as a benchmark structure for a Research Project financed by the Italian Department of Civil Protection (named ReLUIS-DPC 2010-2013) to which this study belongs, with the aim of developing careful seismic assessment analyses, as well as of proposing seismic rehabilitation hypotheses to be possibly applied in the next future. The second building, situated in the province of Florence, was carefully investigated and numerically assessed too. A DB-based retrofit solution similar to the one developed for the first building was also designed, and actually applied in this case, which represents the first practical installation of this dissipative bracing technology to a real structure.

The following contents are particularly presented in the next sections: a synthesis of the characteristics of both buildings; the mechanical parameters, dimensions, layouts and locations selected for the constituting elements of the DB systems designed for their seismic retrofits; the performance assessment analyses in original and rehabilitated conditions developed according to a full non-linear dynamic approach; the renderings of the architectural renovation projects of the 

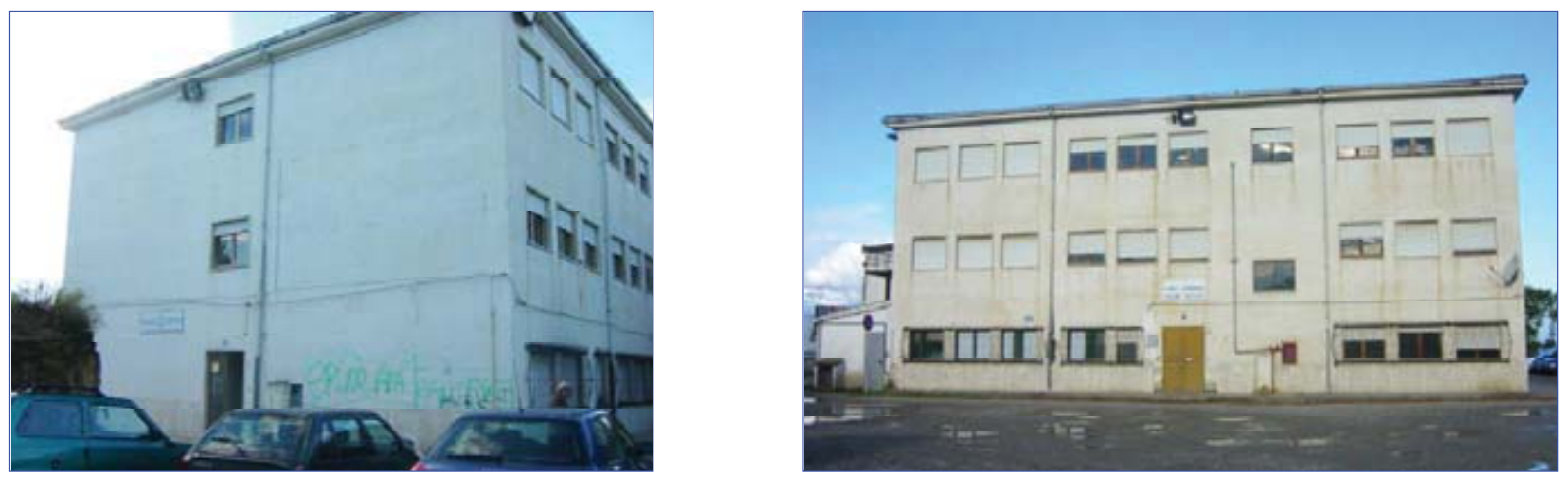

Fig. (1). Views of the building.
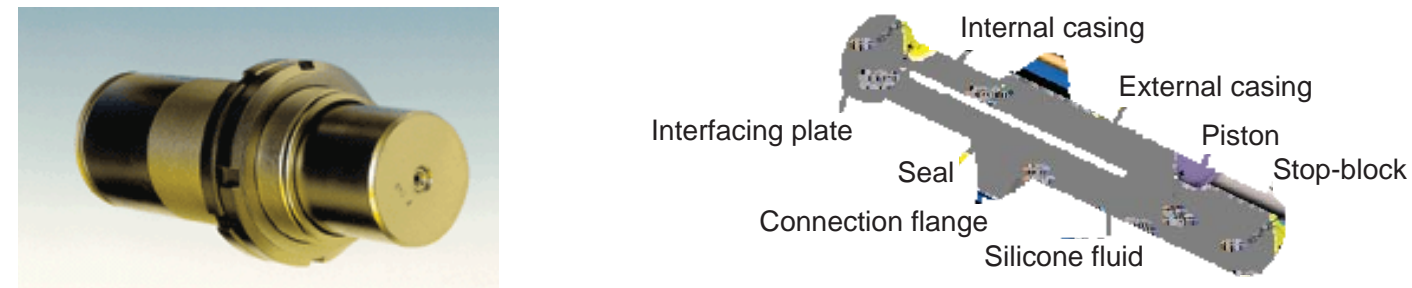

Fig. (2). Photographic view and perspective cross section of a pressurized FV spring-damper.

buildings; and some photographic images relevant to the rehabilitation works of the second one.

\section{FIRST CASE STUDY BUILDING}

\subsection{General Characteristics}

The first case study building is a school in Bisignano, a small town near Cosenza, Calabria - Italy. The building, views of which are displayed in Fig. (1), consists of a threestory $\mathrm{R} / \mathrm{C}$ frame structure, regular both in plan and elevation, designed according to the 1980 edition of Italian Seismic Standards, and completed in 1983. The interstory heights range from about $3.2 \mathrm{~m}$ to about $3.4 \mathrm{~m}$, for a total height of about $9.9 \mathrm{~m}$ at the under-roof level. The roof is supported by a set of small brick walls erected over the floor slab. The structure of the story floors is $245 \mathrm{~mm}$ thick and made of 200 mm-high prefab R/C joists completed with an on-site concrete cast, parallel to the transversal direction in plan (coinciding with the direction of $y$ axis of the reference coordinate system, as shown in the drawings in Fig. (3), presented in section 2.4); clay lug bricks; and a $45 \mathrm{~mm}$ thick upper $\mathrm{R} / \mathrm{C}$ slab. The structures of the under-roof floor and the roof are similar, except for a reduced thickness of the upper R/C slab, equal to $30 \mathrm{~mm}$. The primary beams, parallel to the longitudinal $(x)$ direction, have a mutual section of $(400 \times 600)$ $m m \times m m$. The secondary beams placed on the two side fronts, parallel to $y$, have a section of $(500 \times 400) \mathrm{mm} \times \mathrm{mm}$; the internal secondary beams have a section of $(300 \times 250)$ $\mathrm{mm} \times \mathrm{mm}$, except for the two beams adjacent to the stairs, with sections of $(600 \times 250) \mathrm{mm} \times \mathrm{mm}$-left beam, and $(300 \times 400) \mathrm{mm} \times \mathrm{mm}$. The columns have a mutual section of $(500 \times 400) \mathrm{mm} \times \mathrm{mm}$, equal for the three stories, with the larger side parallel to the $x$ axis. This results in a set of four main frame alignments parallel to the same axis $(x)$, and six secondary frame alignments parallel to $y$. The foundations are constituted by a mesh of inverse T-shaped R/C beams, with a mutual $1000 \mathrm{~mm}$-high and $1000 \mathrm{~mm}$-wide section, a $300 \mathrm{~mm}$-high flange and a $500 \mathrm{~mm}$-wide web.

\subsection{Modal Parameters in Original Conditions}

The modal analysis carried out by the complete finite element model of the structure showed that the first vibration mode is purely translational along $y$, with a period of $0.98 \mathrm{~s}$, and an effective modal mass (EMM) equal to $78.9 \%$ of the total seismic mass. The third mode is purely translational along $x$, with period of $0.52 \mathrm{~s}$ and EMM equal to $82.9 \%$. The fourth and sixth modes are again purely translational along $y$ and $x$, with periods of $0.26 \mathrm{~s}$ and $0.16 \mathrm{~s}$, and EMMs of $15 \%$ and $12.6 \%$, respectively. By summing up these EMM values and the ones of the first and third modes, total EMMs of $93.9 \%$, and $95.5 \%$ are obtained for the two first translational modes in $y$ and $x$. The second and fifth modes are purely rotational around the vertical axis $z$, with EMMs equal to $30.5 \%$ and $23.6 \%$. These data are in good agreement with the results of dynamic characterization tests carried out on the building, and highlight that the structure is not appreciably affected by the torsional components of response, reflecting its substantial regularity in plan (with the only exception of stairs, placed in a slightly eccentric position) and elevation.

\subsection{Characteristics of FV Devices Incorporated in the DB System}

As shown in Fig. (2), the pressurized FV spring-dampers incorporated in the dissipative bracing system examined in this study consist of an internal cylindrical casing, filled with a silicone fluid pressurized by a static pre-load applied upon manufacturing; a piston moving in this fluid; and an external casing. The operating mechanism is based on the silicone fluid flowing through the thin annular space found between the piston head and the internal casing $[23,24]$. The inherent 

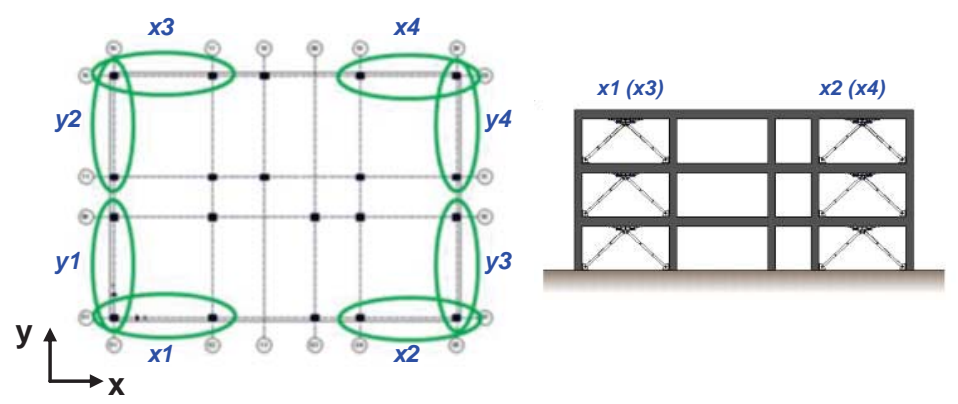
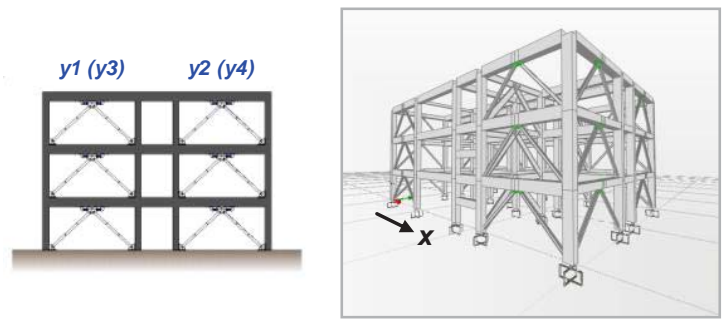

Fig. (3). Distribution of DB alignments in plan and elevation.

re-centering capacity of the device is ensured by the initial pressurization of the fluid $[23,25]$.

The total dynamic reaction force exerted by the device is the sum of $F_{\mathrm{d} 0}(t)$ damping and $F_{\mathrm{d} 0}(t)$ non-linear elastic reaction forces corresponding to their damper and spring functions, respectively. $F_{\text {do }}(t)$ and $F_{\text {ne }}(t)$ can be expressed analytically as follows [6, 23]:

$$
\begin{aligned}
& F_{\mathrm{d}}(t)=c \operatorname{sgn}(\dot{x}(t))|\dot{x}(t)|^{\alpha} \\
& F_{\text {ne }}(t)=k_{2} x(t)+\frac{\left(k_{1}-k_{2}\right) x(t)}{\left[1+\left|\frac{k_{1} x(t)}{F_{0 \mathrm{~d}}}\right|^{\mathrm{R}}\right]^{1 / \mathrm{R}}}
\end{aligned}
$$

where: $c=$ damping coefficient; $\operatorname{sgn}(\cdot)=$ signum function; $|\cdot|=$ absolute value; $\alpha=$ fractional exponent, ranging from 0.1 to $0.2 ; F_{0 \mathrm{~d}}=$ static pressurization pre-load; $k_{1}, k_{2}=$ stiffness of the response branches situated below and beyond $F_{0 \mathrm{~d}}$; and $R=$ integer exponent, set as equal to $5[13,23,26]$.

The finite element model of FV spring-dampers is obtained by combining in parallel a non-linear dashpot element and a non-linear spring element with reaction forces given by Eqs. (1) and (2), respectively. Both types of elements are currently incorporated in commercial structural analysis programs, such as the SAP2000NL code used in the numerical sections of this study [27]. In this assembly, the static preload $F_{0 \mathrm{~d}}$ is imposed as an internal force to a bar linking the two elements. In order to simulate the attainment of the spring-damper strokes, the device model can be completed with a "gap" element and a "hook" element, aimed at disconnecting the device when stressed in tension, and at stopping it when the maximum displacement in compression is reached, respectively [13-14, 22-23].

\subsection{DB-based Retrofit Intervention Proposal}

The choice of the DB system as seismic retrofit solution for this building, as well as for the second case study one, was the result of a comprehensive design process where other advanced rehabilitation strategies, among which base isolation, were preliminarily hypothesised and sized. The advantages offered by the DB technology as compared to base isolation consist in the considerably quicker installation times, shorter interruption in the use of the buildings and lower costs, as a consequence of the little number of FV spring-dampers and relevant supporting braces needed, in total, to reach the same design performance objectives.
Within the field of dissipative bracing technologies, the selected type of FV devices was compared with other classes of commercial dampers adopted in the seismic retrofit of frame structures. FV spring-dampers were preferred to metallic hysteretic dissipaters, characterized by competitive costs, for the two following reasons: total absence of damage at any response step, as opposed to the damaged response of metallic dampers, which dissipate seismic energy through their plastic deformation cycles; and the self-centering capacities ensured by the pressurization of FV devices, which allows avoiding any residual displacement in the dissipaters at the end of the earthquake shaking. On the other hand, competitive performance could be reached by Shape Memory Alloy (SMA) dissipaters or friction dampers, both in terms of non-damageability and self-centering capacity (when the devices also include some elastic spring element), but at notably higher costs, for SMA-based solutions, and dimensions, for friction-based ones. Therefore, the FV-DB system resulted to be the most effective performance/cost retrofit design for the two case study structures.

By considering the characteristics of substantial regularity of Bisignano building remarked in section 2.1, the braces may be preferably placed along the perimeter, so as to preserve the symmetrical layout of the structure and avoid all obstructions to the interiors. At the same time, this choice allows retrofitting only the two secondary (parallel to $y$ ) frames that include the most robust beams, in addition to the external primary frames. The positions of the DB system alignments ( $x 1$ through $x 4, y 1$ through $y 4$ ) are shown in Fig. (3), where the plan and elevation schemes in rehabilitated conditions, as well as a 3-D view of the corresponding finite element model, are displayed.

The details of installation of the DB system correspond to a general layout conceived at previous steps of this research $[9,10,13,14]$, and already applied to the test structures enquired in the experimental sections of the study $[9,10,13$, 22]. This layout, specialized to the Bisignano building in Fig. (4), consists in a couple of interfaced FV devices mounted at the tip of each pair of supporting steel braces. A half-stroke initial position is imposed on site to the pistons of both spring-dampers, so as to obtain symmetrical tensioncompression response cycles, starting from a compressiveonly response of the single devices. This position is obtained by introducing a pair of threaded steel bars through a central bored plate orthogonal to the interfacing plate of each device, and connecting the bars to two other bored plates, screwed into the external casing of the spring-dampers. The 

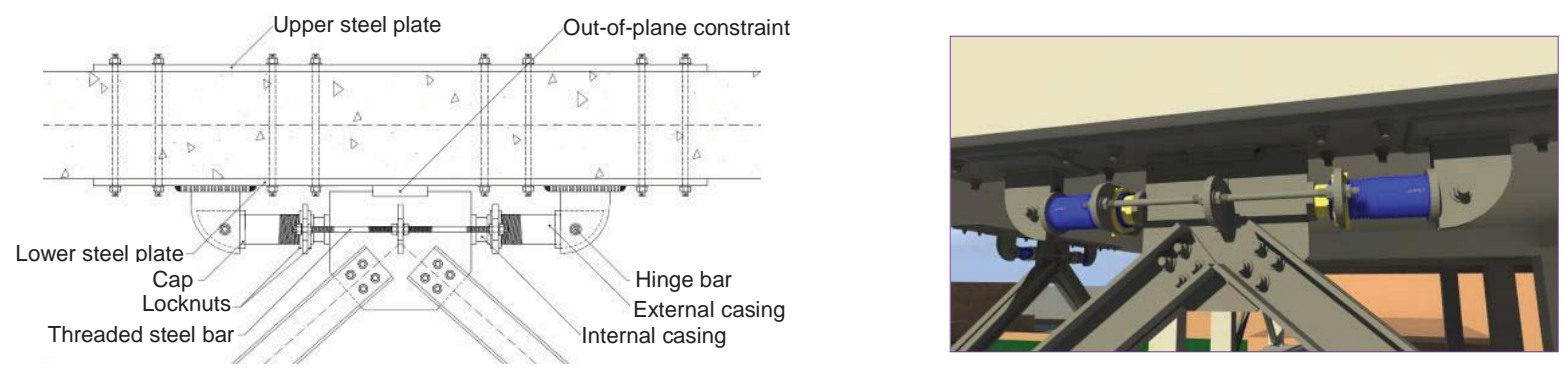

Fig. (4). Basic installation layout of FV spring-dampers designed for the Bisignano building.

terminal section of the external casing of each FV device is encapsulated into a steel "cap" hinged to a pair of vertical plates fixed to the lower face of the floor beam. A vertical plate finished with a Teflon sheet is placed on both faces of the interfacing plate, so as to constrain accidental out-ofplane displacements of the system assembly, which is fixed to the $\mathrm{R} / \mathrm{C}$ floor beam by an upper and a lower steel plates linked by vertical steel connectors passing through the beam.

The performance evaluation enquiry was carried out for the four reference seismic levels established by current Italian Standards [28], that is, Frequent Design Earthquake (FDE, with a $81 \%$ probability of being exceeded over the reference time period $V_{\mathrm{R}}$ ); Serviceability Design Earthquake (SDE, with a $50 \% / V_{\mathrm{R}}$ probability); Basic Design Earthquake (BDE, with a $10 \% / V_{\mathrm{R}}$ probability); and Maximum Considered Earthquake (MCE, with a $5 \% / V_{\mathrm{R}}$ probability). The $V_{\mathrm{R}}$ period is fixed at 50 years, which is obtained by multiplying the nominal structural life $V_{\mathrm{N}}$ of 50 years by a coefficient of use equal to 1 , normally adopted for school or public buildings not subjected to crowded affluence. By referring to topographic category T1 (flat surface), and C-type soil (deep deposits of dense or medium-dense sand, gravel or stiff clay from several ten to several hundred metres thick), the peak ground accelerations for the four seismic levels are as follows: $0.106 \mathrm{~g}$ (FDE), $0.142 \mathrm{~g}$ (SDE), $0.357 \mathrm{~g}$ (BDE), and $0.424 \mathrm{~g}$ (MCE). Seven artificial accelerograms generated from the four elastic pseudo-acceleration response spectra (the BDE-scaled of which is plotted in Fig. 5) were used as inputs to the non-linear dynamic analyses.

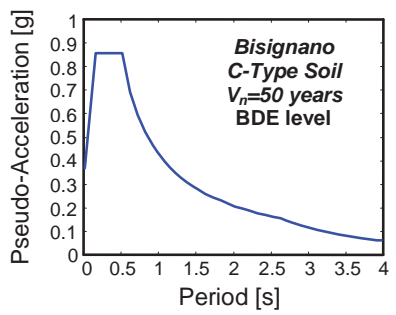

Fig. (5). Elastic response spectrum for Bisignano, BDE level, $V_{\mathrm{n}}=50$ years, $C_{\mathrm{u}}=1$, topographic category $\mathrm{T} 1$, and C-type soil.

For these analyses, lumped plastic hinges governed by a classical Takeda-type relationship [29] were introduced in the finite element model of the original structure at the end sections of beams and columns. Results were elaborated in mean values over the sets of input ground motions. The seismic performance was assessed by referring to the criteria and limitations of ASCE 41-06 Recommendations for the structural rehabilitation of existing buildings [30]. The maximum interstory drift ratio $I D_{\mathrm{r}, \max }$ (i.e. the ratio of maximum interstory drift to interstory height) and the maximum plastic rotations $\vartheta_{\mathrm{pl}, \max }$ in beams and columns were assumed as basic response parameters in the evaluation analysis. The poorest performance was observed on the second story along $y$ axis, which constitutes the most vulnerable direction in plan, for all earthquake levels. The response was totally elastic for FDE and SDE, with $I D_{\mathrm{r}, \max }$ equal to $0.57 \%$ (FDE) and $0.76 \%$ (SDE). Both values are below the reference drift limit for the Immediate Occupancy (IO) structural performance level, fixed at $1 \%$ for existing $\mathrm{R} / \mathrm{C}$ frame buildings by [30], as well as by other international Standards and Recommendations. Concerning BDE, activation of about $45 \%$ of plastic hinges in the entire model, and maximum interstory drift ratios of $2.8 \%$ on the second story along $y$, were found. The maximum plastic rotation angles amounted to 0.014 radians in the beams parallel to $y$, and to 0.011 radians in columns. This means that performance does not meet the drift limitation of 2\%, relevant to the Life Safety (LS) level (although the plastic rotation limits of 0.015 radians for beams and 0.013 radians for columns, calculated for the geometric and reinforcement characteristics of these members, are met), and as a consequence it falls within the Limited Safety (LimS) structural performance range. The number of activated plastic hinges increases to $70 \%$ for the input action scaled at the MCE amplitude, with $\vartheta_{\mathrm{pl}, \text { max }}$ equal to 0.018 radians in beams parallel to $y$ and 0.015 radians in columns, and $I D_{\mathrm{r}, \max }$ equal to $3.5 \%$. These values are just below the minimum requirements for the Collapse Prevention (CP) level (mutual rotation limit of 0.02 radians for beams and columns, and allowable drift threshold of 4\%). A slightly better performance emerges for the $x$ direction (the second story being the most stressed along this axis too), where the FDE-IO, SDE-IO, and MCE-CP earthquake levelsstructural performance levels correlations already found for $y$ are assessed again, whereas a better correlation (LS instead of LimS) comes out for the BDE.

Based on the results of the assessment analysis in current conditions, the performance objectives postulated in the retrofit design consisted in reaching: a Damage Control (DC) structural level for BDE, with at most some slight plastic rotations (i.e. limited below 0.003 radians) in few beams, and $1.5 \%$ maximum interstory drift ratios; a LS structural level for MCE, with more extended but easily reparable plastic rotations (i.e. limited below 0.005 radians) in beams and columns, and $2 \% I D_{\text {r,max }}$ values; an IO non-structural level for SDE, assessed by $0.5 \%$ maximum drift ratios (satisfied by the original structure in $x$ direction, but not in $y$, as men- 

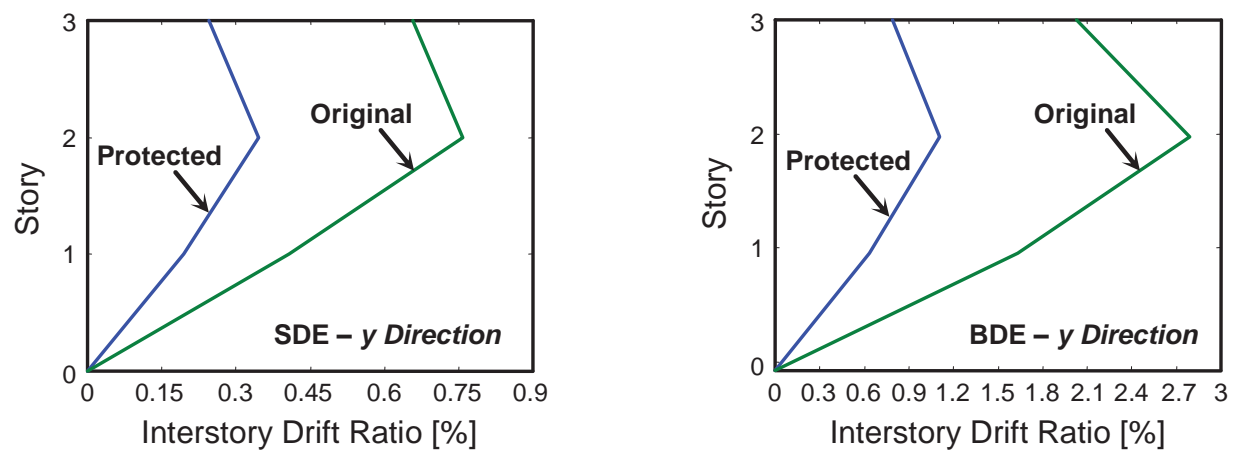

Fig. (6). Maximum interstory drift profiles in $y$ direction (mean values).
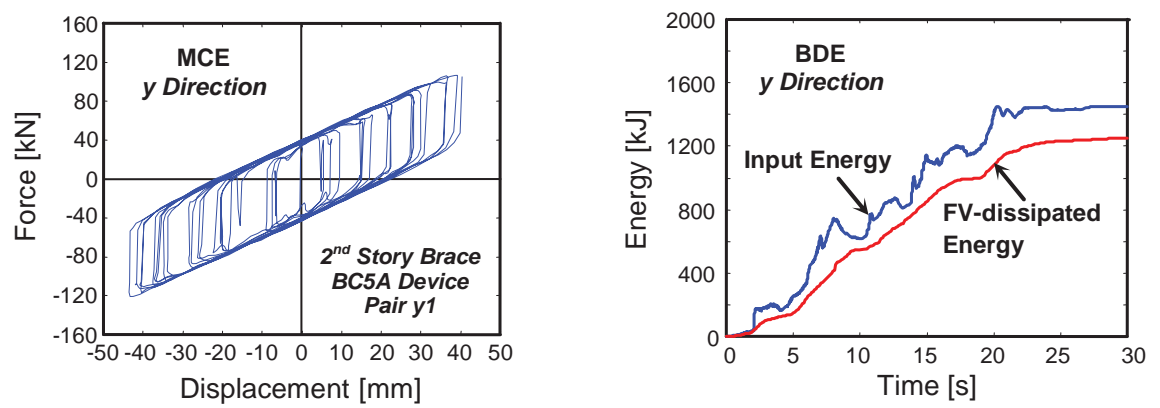

Fig. (7). Response cycles of most stressed BC5A spring-damper pair, and energy time-histories in $y$ direction obtained from the most demanding MCE and BDE-scaled input accelerogram, respectively.

tioned above), in order to obtain an elastic structural response and prevent any appreciable damage of partitions and infills; and an Operational (OP) structural and non-structural level for FDE, identified by a $0.33 \% I D_{\mathrm{r}, \max }$ limit, so as to obtain a totally undamaged response of partitions and infills, as well as of any other non-structural member. Four alignments (and thus four pairs of FV devices) per direction were adopted on each story, as sketched in Fig. (3). The following damping coefficient demands emerged from the design analysis for each device belonging to the four pairs to be installed per direction: $c=34 \mathrm{kN}(\mathrm{s} / \mathrm{m})^{\alpha}$ (with $\alpha=0.15$ ), $c=48$ $\mathrm{kN}(\mathrm{s} / \mathrm{m})^{\alpha}$, and $c=22 \mathrm{kN}(\mathrm{s} / \mathrm{m})^{\alpha}$, on the first, second, and third stories, respectively, for $y$; and $c=26 \mathrm{kN}(\mathrm{s} / \mathrm{m})^{\alpha}, c=34$ $\mathrm{kN}(\mathrm{s} / \mathrm{m})^{\alpha}$, and $c=16 \mathrm{kN}(\mathrm{s} / \mathrm{m})^{\alpha}$, for $x$. The currently available FV spring-damper that is capable of supplying the damping demands on the first and third stories for both axes, and on the second story for $x$, named BC1GN [31], is characterized by a maximum attainable damping coefficient $c_{\max }=39$ $\mathrm{kN}(\mathrm{s} / \mathrm{m})^{\alpha}$. It can be noted that the different $c$ values listed above are obtained, within the $c_{\max }$ limit, by imposing upon manufacturing different openings of the space between piston head and inner casing surface. A standard device with an immediately greater energy dissipation capacity, characterized by a maximum attainable damping coefficient $c_{\max }=80$ $\mathrm{kN}(\mathrm{s} / \mathrm{m})^{\alpha}$ (named BC5A [31]), is required on the second story of the alignments parallel to $y$.

The final verification analyses were carried out with the finite element model shown in Fig. (3). As way of example of the results obtained, the mean peak drift profiles in original and protected conditions derived for the SDE and BDE input levels are plotted in Fig. (6) for the weakest direction $y$.
A rounded 2.2 reduction factor is observed for the maximum drift ratio at SDE after retrofit, which constrains $I D_{\text {r,max }}$ to $0.35 \%$, that is, far below the target IO threshold of $0.5 \%$. A reduction factor of around 2.3 is obtained for BDE, as the maximum second story drift ratio falls from $2.8 \%$ to $1.1 \%$, then meeting the assumed DC limitation of $1.5 \%$. No plasticization is noticed in the frame members, confirming the attainment of the DC performance level. The $I D_{\mathrm{r}, \max }$ values computed for FDE and MCE are equal to $0.26 \%$ and $1.57 \%$, and meet the targeted OP and LS limits of $0.33 \%$ and $2 \%$, respectively. Slight plasticizations come out at the MCE level for six beams and three columns, with rotation angles lower than 0.002 radians, that is, far below the LS limit of 0.005 radians. Therefore, the LS performance level is reached for MCE.

Based on the results of the performance analysis, no strengthening of the frame members is needed in rehabilitated conditions, as they remain in safe conditions up to the MCE, except for the above-mentioned six beams and three columns. However, these members undergo very slight and easily reparable damage only at this extreme level of seismic action (which does not motivate preventive retrofit interventions). The foundation beams prove to fit in their safe domain too, after the incorporation of the DB system.

As required by [28], a supplemental verification was carried out at the MCE as regards the peak displacements of the FV devices, which must be kept below their net strokes to guarantee the best performance of the protection system at any phase of seismic response. As shown by the response cycles plotted in the left image in Fig. (7), obtained from the most demanding MCE-scaled input accelerogram applied in 

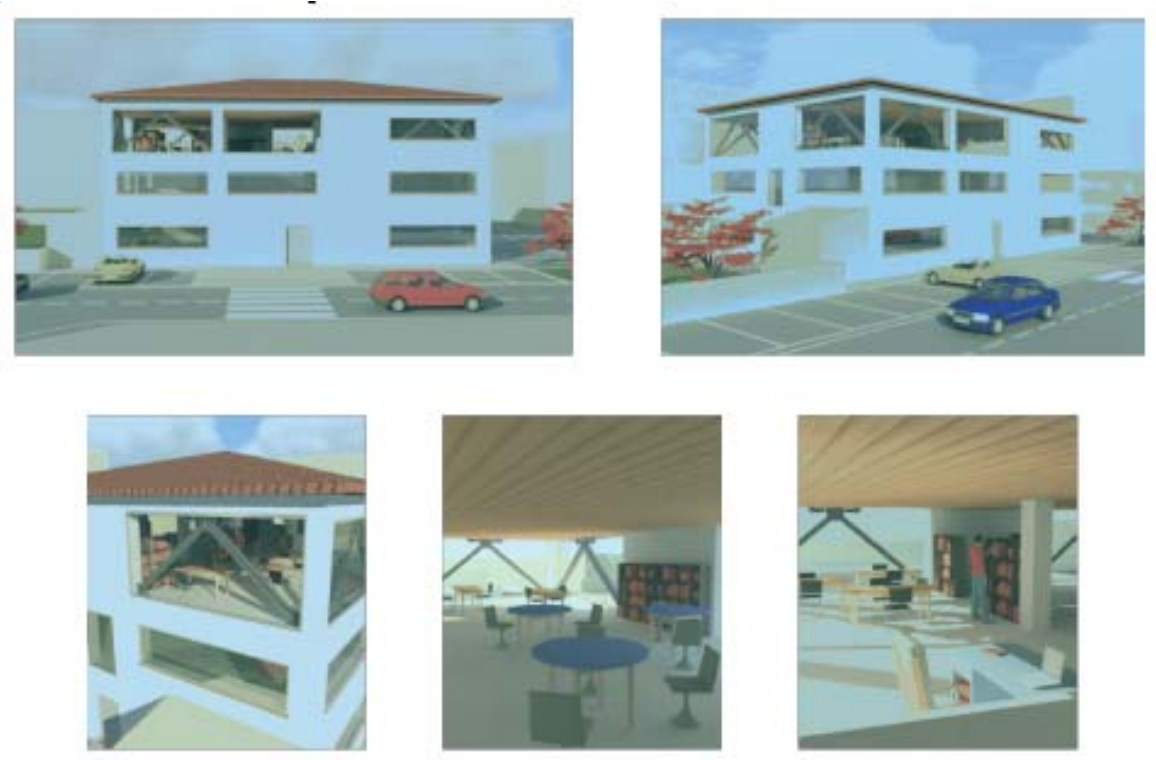

Fig. (8). External and internal renderings of the building after retrofit.

$y$ direction for the most stressed BC5A spring-damper pair mounted on the second floor (situated on the $y l$ alignment in Fig. 3), this additional check is satisfied too.

The same performance objectives obtained along the $y$ direction for FDE, SDE and MCE (FDE-OP, SDE-IO and MCE-LS) are met for the strongest axis $x$, except for BDE, where an upper correlation is found for BDE (BDE-IO instead of BDE-DC). This remarkable improvement of seismic performance is a result of the damping capacity of the DB system, which is normally proportioned $[13,14,21,22]$ in order to absorb $80-90 \%$ of the total dissipated energy on each story, for the two most demanding earthquake levels, i.e. BDE and MCE. This design assumption, adopted for this case study too, is confirmed by the energy responses obtained. Indeed, by considering the median response to the seven input accelerograms, the balance at the end of the input motion shows that the energy dissipated by the 12 pairs of FV spring-dampers is equal to $87 \%$ of the total dissipated energy in this direction, which falls in the $80 \%-90 \%$ targeted range mentioned above. The remaining $13 \%$ is absorbed by modal damping. The fraction dissipated by the FV devices is very similar for the MCE-scaled action (85\%), with $9 \%$ contribution of modal damping, and $6 \%$ given by the slight plastic rotations recorded in beams and columns, in this case. Similar balances come out for the $x$ direction, with the only exception that no contribution of plastic rotations is observed up to the MCE level (83\%-DB system and 17\%-modal damping, at BDE; $88 \%$-DB system and 12\%-modal damping, at MCE). As way of example, the energy timehistories derived from the most demanding BDE-scaled input motion applied in $y$ direction are graphed in the right image in Fig. (7).

The equivalent linear viscous damping ratios computed from the energy responses amount to 29\% (BDE) and 32\% (MCE), in $y$ direction, and to 24\% (BDE) and 27\% (MCE), in $x$. In addition to a drastic cut in interstory drifts, as well as in rotations and stresses of frame members, these damping measures also explain the drop in the total base shear of the structure, which is reduced by $46 \%$ (BDE) and $51 \%$ (MCE) in $y$ direction, and by $40 \%$ (BDE) and $43 \%$ (MCE) in $x$, when passing from original to retrofitted conditions.

Some renderings of the whole building and the upper floor interiors after retrofit are reproduced in Fig. (8). These drawings show the incorporation of DB system and the improved look of the building obtained thanks to its architectural refurbishment design, where the addition of the dissipative braces is emphasized through large glazed windows on the top floor, and particularly to the left side of the building, which accommodates the school library.

The estimated costs of the structural works amount to 140 Euros $/ \mathrm{m}^{2}$, which are $30 \%$ to $35 \%$ lower than the cost of conventional rehabilitation designs (200-220 Euros $\left./ \mathrm{m}^{2}\right)$, which were also developed to establish a price comparison with the dissipative bracing protection solution. These designs consist in incorporating $\mathrm{R} / \mathrm{C}$ walls or traditional undamped bracings in the same alignments as in the DB system, and jacketing the existing frame elements (for a total of $40 \%$ of columns, and $55 \%$ of beams) with steel profiles or fiber reinforced plastics.

\section{SECOND CASE STUDY BUILDING}

\subsection{General Characteristics}

The second case study is a school building too, situated in Borgo San Lorenzo, a town in the province of Florence. The original structural design was developed in the early 1970s and adapted, in 1975, to the requirements of the first edition of Italian Seismic Standards. The construction works were completed at the end of 1976. The building, views of which in pre-retrofit conditions are shown in Fig. (9), consists of a two-story R/C frame structure and is composed of two wings with rectangular plan. The wing on the left side with respect to the main street presents a "pilotis" configura- 

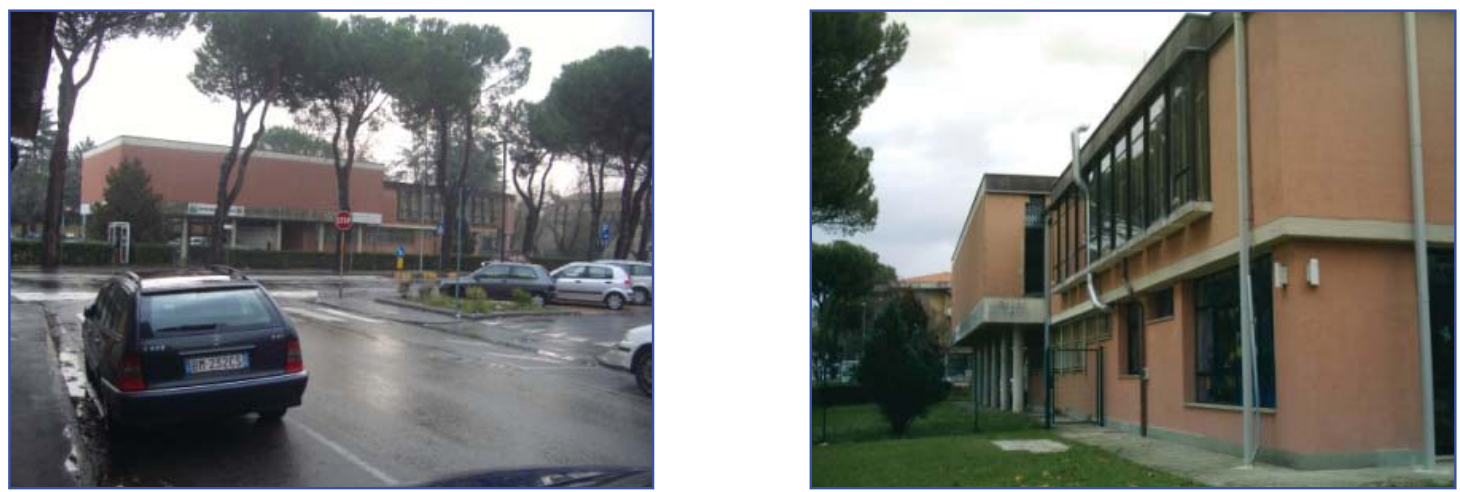

Fig. (9). Views of the building before the seismic retrofit and architectural renovation interventions.

tion on the ground floor, whereas the second wing is totally infilled.

The interstory heights are equal to $4.1 \mathrm{~m}$ (ground floor) and $3.7 \mathrm{~m}$ (first floor), on the pilotis side; and $3.3 \mathrm{~m}$ (ground floor) and $3.7 \mathrm{~m}$ (first floor), on the infilled side. The roof is flat. The structure of the story and roof floors is $220 \mathrm{~mm}$ thick in the pilotis wing, and $280 \mathrm{~mm}$ thick in the infilled wing, and is made of on-site cast $\mathrm{R} / \mathrm{C}$ joists, clay lug bricks, and a $40 \mathrm{~mm}$ thick upper $\mathrm{R} / \mathrm{C}$ slab. The axes of the beams of the pilotis wing, which have a mutual $\mathrm{T}$-shaped section with a $500 \mathrm{~mm}$-high flange and a $300 \mathrm{~mm}$-wide and $550 \mathrm{~mm}$-high web, are drawn according to a rhomboidal plot on both floors. The beams of the infilled wing, instead, present a usual orthogonal plot and they all have in-depth sections. The dimensions of the primary beams, parallel to the longitudinal $(x)$ direction, are $(1200 \times 280) \mathrm{mm} \times \mathrm{mm}$, in the internal frame alignments, and $(800 \times 280) \mathrm{mm} \times \mathrm{mm}$, in the perimeter ones. The secondary beams (parallel to $y$ ), with section of $(400 \times 280) \mathrm{mm} \times \mathrm{mm}$, are placed only on the two side fronts. The stairs have a steel frame structure, and are located outside the building, with a wide seismic separation joint with respect to it. The columns have a mutual circular section with $350 \mathrm{~mm}$ diameter in the pilotis wing on both stories; and a rectangular section of $(300 \times 400) \mathrm{mm} \times \mathrm{mm}$ or a square section of $(400 \times 400) \mathrm{mm} \times \mathrm{mm}$ on the ground story, which reduces to a rectangular section of $(300 \times 350)$ $m m \times m m$ or a square section of $(350 \times 350) \mathrm{mm} \times \mathrm{mm}$ on the first story, in the infilled wing. The foundations are constituted by a mesh of rectangular R/C beams, with a mutual section of $(700 \times 700) \mathrm{mm} \times \mathrm{mm}$. The base is enlarged to 1200 $\mathrm{mm}$, for a length of $1200 \mathrm{~mm}$, below the most loaded columns of the infilled wing.

\subsection{Modal Parameters in Original Conditions}

The modal analysis showed that the six main vibration modes (i.e. the modes capable of determining a summed EMM greater than $85 \%$ of the total seismic mass along all three reference axes, according to the basic request of [28]) are mixed rotational around the vertical axis $z$-translational along $y$ (first, third and fifth mode), and mixed rotational around the vertical axis $z$-translational along $x$ (second, fourth and sixth mode). The computed periods and EMMs are as follows: $0.81 \mathrm{~s}, 53.6 \%$ along $y$ and $39.8 \%$ around $z-$ first mode; $0.36 \mathrm{~s}, 21.8 \%$ along $y$ and $29.2 \%$ around $z$-third mode; $0.15 \mathrm{~s}, 14.3 \%$ along $y$ and $18.5 \%$ around $z$-fifth mode; $0.56 \mathrm{~s}, 57.4 \%$ along $y$ and $34.3 \%$ around $z-$ second mode; 0.25 s, $23.1 \%$ along $y$ and $30.7 \%$ around $z$-fourth mode; 0.11 s, $11.8 \%$ along $y$ and $20.9 \%$ around $z$-sixth mode. These data underline that, unlike the Bisignano building, the structure is appreciably affected by the torsional components of response, as a consequence of the irregularity in plan and elevation caused by the geometric differences of the two wings, as well as by their staggered positions in plan.

\subsection{DB-based Retrofit Intervention}

The design of the retrofit and architectural renovation interventions was carried out by a local professional office, coordinated by the structural engineers Fausto and Enrico Giovannardi, who applied the DB system devised by the authors of this paper as seismic rehabilitation strategy. The first author acted as tester of the structural works, the images of which presented in this section were taken during this institutional activity. All the results reported in the paper were obtained by independent analyses, elaborations and verifications carried out by the authors with respect to those developed by the designers.

The dissipative braces were placed in the two right corners of the originally infilled wing and in proximity to the two left corners of the pilotis wing (Fig. 10). This allowed effectively restraining the torsional seismic response effects, while at the same time avoiding all obstructions to the interiors, like in the Bisignano building. Concerning the pilotis wing, due to the rhomboidal plot of the beams, in order to properly install the dissipative braces along the two main directions in plan, it was necessary to build two new R/C beams parallel to $x$ on both floors, and to incorporate a ground-to-roof steel frame parallel to $y$, as shown in the photographic images reported at the end of this section (Figs. 15-19).

The details of installation of the DB system were elaborated by the designers by varying some details as compared to the general layout discussed for the Bisignano building. As illustrated in Fig. (11), the main modification consists in imposing the half-stroke initial position of the interfaced FV devices by acting on a big worm screw placed behind each spring-damper, screwed to a vertical plate orthogonal to the longitudinal axis of the devices. In addition to these two plates, other four vertical plates, parallel to the springdampers and enclosing them, and a central trapezoidal plate to which the diagonal braces are bolted, complete the "boxed" installation assembly. This is fixed to the $\mathrm{R} / \mathrm{C}$ floor 

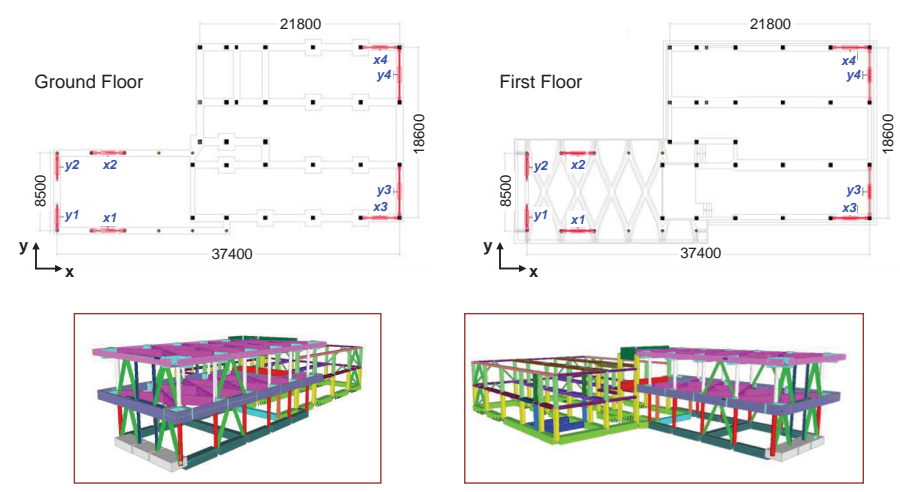

Fig. (10). Distribution of DB alignments in plan and elevation.
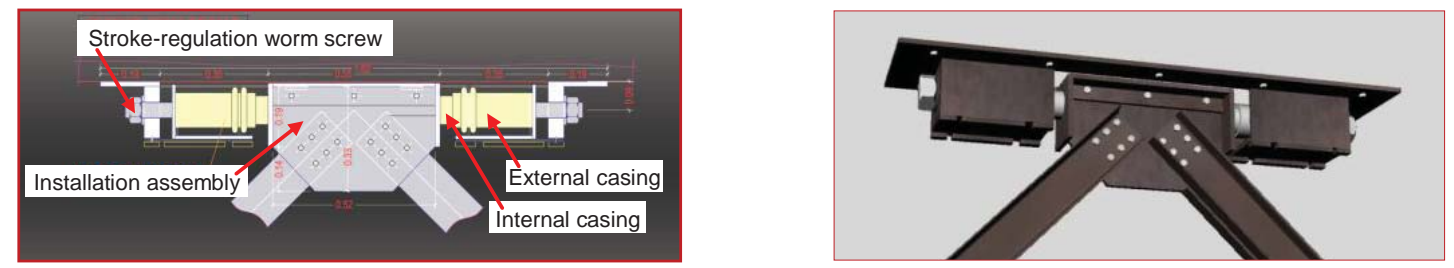

Fig. (11). Special installation layout of FV spring-dampers designed for the Borgo San Lorenzo building.

beam by an upper steel plate, linked by vertical steel connectors passing through the beam, as in the general layout of the system.

The performance evaluation enquiry was carried out for the same four reference seismic levels established by [28], described above for the Bisignano building. The $V_{R}$ period (50 years), topographic category (T1), and soil type (C) are the same as for that case study. The resulting peak ground accelerations are as follows: $0.093 \mathrm{~g}$ (FDE), $0.119 \mathrm{~g}$ (SDE), $0.278 \mathrm{~g}$ (BDE), and $0.335 \mathrm{~g}$ (MCE). Seven artificial accelerograms generated from the four elastic pseudo-acceleration response spectra (the BDE-scaled of which is plotted in Fig. 12) were used as inputs to the non-linear dynamic analyses in this case too.

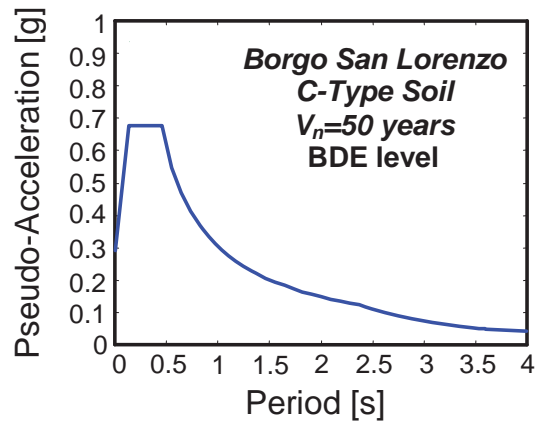

Fig. (12). Elastic response spectrum for Borgo San Lorenzo, BDE level, $V_{\mathrm{n}}=50$ years, $C_{\mathrm{u}}=1$, topographic category $\mathrm{T} 1$, and C-type soil.

The analyses were carried out by following the same methodology adopted for the Bisignano building. The poorest performance was observed on the second story along $y$ axis, for all earthquake levels. The response was totally elastic for FDE and SDE, with $I D_{\mathrm{r}, \max }$ equal to $0.78 \%$ (FDE) and $1 \%$ (SDE). The first value is below, and the second value is just equal to the $1 \%$ drift limit for the Immediate Occupancy (IO) structural performance level. Concerning BDE, activation of about $60 \%$ of plastic hinges in the entire model, and maximum interstory drift ratios of $3.5 \%$ on the second story along $y$, were found. The maximum plastic rotation angles $\vartheta_{\text {pl,max }}$ amounted to 0.019 radians in the beams parallel to $y$, and to 0.015 radians in columns. These values are just below the minimum requirements for the $\mathrm{CP}$ level. The number of activated plastic hinges increases to $85 \%$ for the input action scaled at the MCE amplitude, with $\vartheta_{\text {pl,max }}$ equal to 0.025 radians in beams parallel to $y$ and 0.022 radians in columns. At the same time, $I D_{\mathrm{r}, \max }$ increases to $4.3 \%$. These data situate the MCE-related performance beyond all CP level limitations. As for the Bisignano building, a slightly better performance is found for the $x$ direction (the second story being the most stressed along this axis too), where FDE-IO, SDEIO, BDE-CP and MCE-CP earthquake levels-structural performance levels correlations are assessed.

The performance objectives for the retrofit design coincide with the ones assumed for the Bisignano building. Four alignments per direction were adopted on both stories, as shown in Fig. (10). The following damping coefficient demands emerged from the design analysis for each device belonging to the four pairs to be installed per direction: $c=25$ $\mathrm{kN}(\mathrm{s} / \mathrm{m})^{\alpha}$, and $c=33 \mathrm{kN}(\mathrm{s} / \mathrm{m})^{\alpha}$ (with $\alpha=0.15$ ) on the first and second stories, respectively, for $y$; and $c=16 \mathrm{kN}(\mathrm{s} / \mathrm{m})^{\alpha}$, and $c=23 \mathrm{kN}(\mathrm{s} / \mathrm{m})^{\alpha}$, for $x$. Therefore, based on their $c_{\max }=39$ $\mathrm{kN}(\mathrm{s} / \mathrm{m})^{\alpha}$ maximum damping capacity discussed above, $\mathrm{BC} 1 \mathrm{GN}$ devices were adopted for both stories and directions in this case.

Similarly to Bisignano, the mean peak interstory drift ratio profiles in original and protected conditions derived from the final verification analyses are plotted in Fig. (13), for the SDE and BDE input levels, and the weakest direction $y$.

For the structure in Borgo San Lorenzo too, a rounded 2.2 reduction factor is observed for $I D_{\mathrm{r}, \max }$ at SDE after retrofit, which constrains $I D_{\mathrm{r} \text {,max }}$ to $0.41 \%$, that is, below the target IO threshold of $0.5 \%$. A reduction factor of around 3.2 is obtained for BDE, with $I D_{\text {r,max }}$ falling from $3.45 \%$ to $1.06 \%$, 

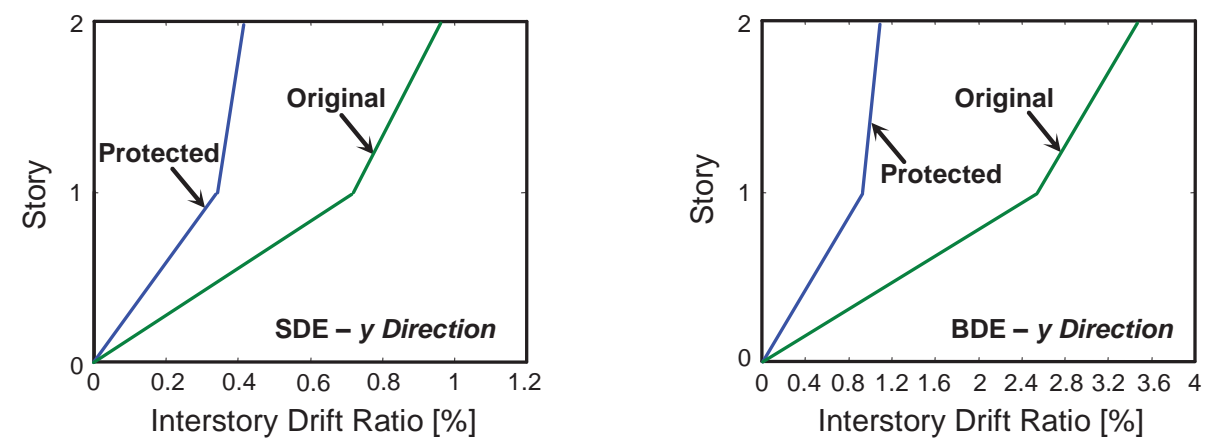

Fig. (13). Maximum interstory drift profiles in $y$ direction (mean values).
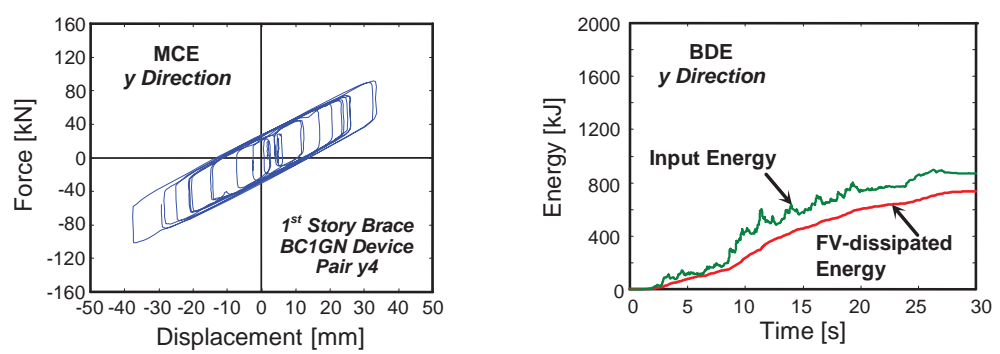

Fig. (14). Response cycles of most stressed BC1GN spring-damper pair, and energy time-histories in $y$ direction obtained from the most demanding MCE and BDE-scaled input accelerogram, respectively.

which allows meeting the DC limitation of $1.5 \%$. As no plasticization is observed in the frame members, the DC level requirements are definitely met for the BDE level. The $I D_{\mathrm{r}, \max }$ values computed for FDE and MCE are equal to $0.31 \%$ and $1.43 \%$, and meet the targeted OP and LS limits of $0.33 \%$ and $2 \%$, respectively. Slight plasticizations come out at the MCE level for three columns, with rotation angles no greater than 0.004 radians, that is, below the LS limit of 0.005 radians. Therefore, the LS performance level is reached for MCE.

The three columns affected by plastic rotations at MCE also result to fall outside their safety domain in static conditions, under the effects of the gravitational loads only. Therefore, a strengthening intervention was needed for these originally undersized columns, consisting in a simple steel jacketing solution, regardless of the benefits induced by the DB-based seismic retrofit design. The foundation beams are within their safe domain too, after the incorporation of the DB system, except for the perimeter beam situated on the left of the pilotis wing, where an additional steel frame was introduced to install the dissipative braces, as commented above. An enlargement of the base of this beam from 700 $\mathrm{mm}$ to $1500 \mathrm{~mm}$ was designed to this aim.

The peak displacements of the FV devices at MCE are always kept below their net strokes. As way of example, the response cycles obtained from the most demanding MCEscaled input accelerogram applied in $y$ direction for the most stressed spring-damper pair mounted on the second floor (situated on the upper right corner of the infilled wing), are plotted in the left image in Fig. (14).

Similarly to the Bisignano building, the same performance objectives obtained along the $y$ direction for FDE, SDE and MCE (FDE-OP, SDE-IO and MCE-LS) are met for the strongest axis $x$, except for $\mathrm{BDE}$, where an upper correlation is found for BDE (BDE-IO instead of BDE-DC).

The energy time-histories derived from the most demanding BDE-scaled input motion applied in $y$ direction, plotted in the right image in Fig. (14), substantially duplicate the energy balances already found for the first case study building. Indeed, by considering the median response to the seven input accelerograms, the balance at the end of the input motion shows that the energy dissipated by the 8 pairs of FV spring-dampers is equal to $88 \%$ of the total dissipated energy in this direction, with the remaining $12 \%$ absorbed by modal damping. For the MCE-scaled action, the fractions are: $86 \%$ by $\mathrm{FV}$ devices, $10 \%$ by modal damping, and $4 \%$ given by the plastic rotations of columns. Similar balances come out, for the building in Borgo San Lorenzo too, for the $x$ direction, where no plasticizations are observed for MCE.

The total base shear of the structure is reduced by $52 \%$ (BDE) and 55\% (MCE) in $y$ direction, and by $44 \%$ (BDE) and $46 \%$ (MCE) in $x$, when passing from original to retrofitted conditions. The equivalent linear viscous damping ratios computed from the energy responses amount to $31 \%$ (BDE) and $35 \%$ (MCE), in $y$ direction, and to $26 \%$ (BDE) and $30 \%$ (MCE), in $x$ direction.
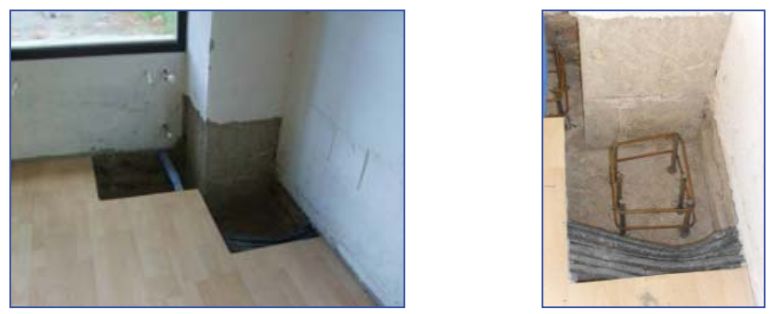

Fig. (15). Preparation of the anchorage zones of braces to the foot of a column. 

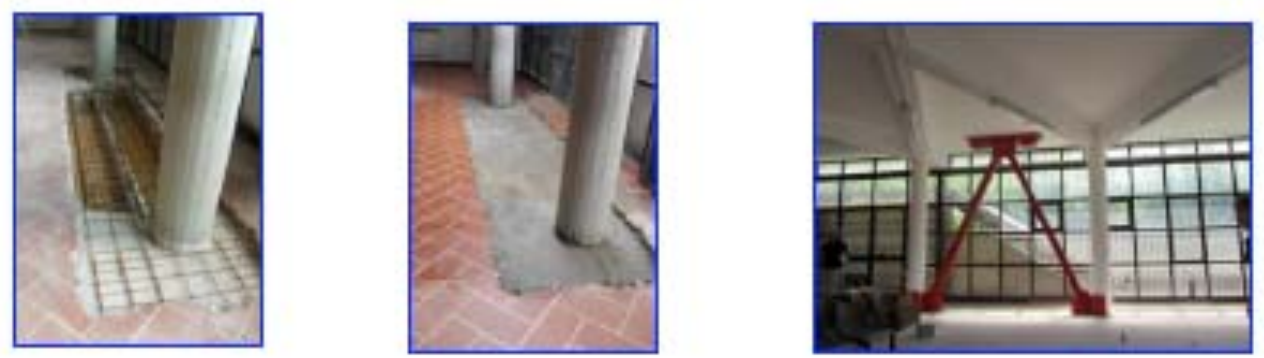

Fig. (16). Construction of the additional R/C beam in one of the two DB alignments parallel to $x$ in the pilotis wing.
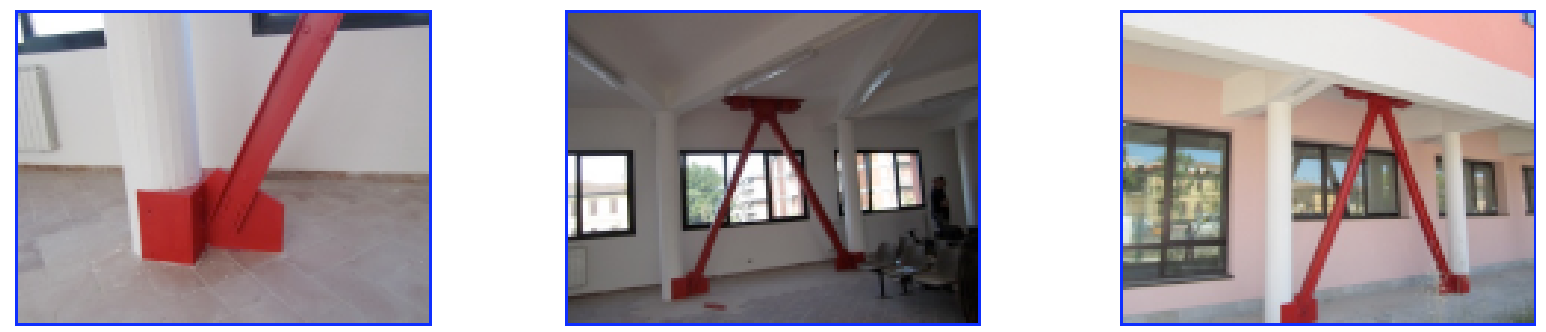

Fig. (17). Detail and general views of the other DB alignment parallel to $x$ in the pilotis wing.
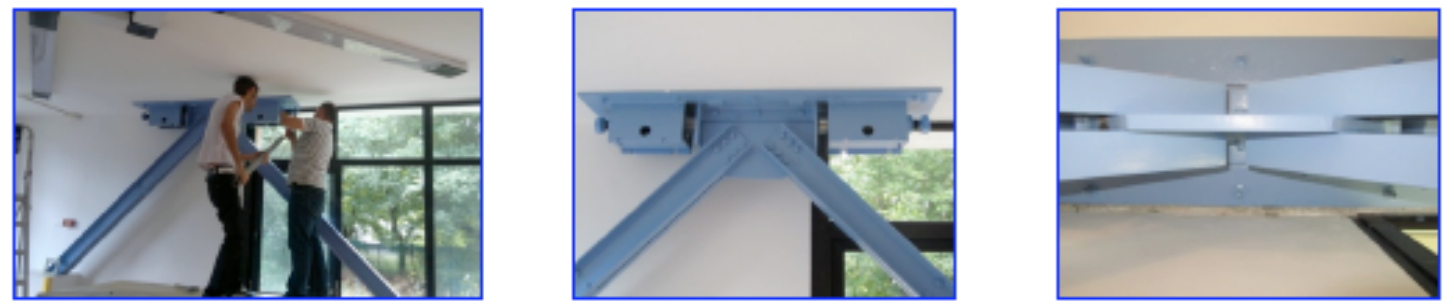

Fig. (18). Final half-stroke positioning of a spring-damper, and views of the same DB panel.

Photographic images taken during the development and at the end of the works are illustrated in Figs. (15) through (19). The preparation of the anchorage zones of the base plates of the diagonal braces at the foot of a column are shown in Fig. (15), highlighting that little local demolitions are required. Views of the additional $\mathrm{R} / \mathrm{C}$ beam included in one of the two DB alignments parallel to $x$ in the pilotis wing, before and after the concrete cast, and the finished dissipative bracing panel are displayed in Fig. (16). In this case too, structural intrusion and demolitions are limited to a minimum. Detail and general (first and ground stories) views of the other DB alignment parallel to $x$ in the pilotis wing, situated on the main façade side, are presented in Fig. (17).

The installation of another DB panel, during the final half-stroke positioning phase of one of the two springdampers by a torque wrench, is visualized in Fig. (18), along with some views of the same panel after the conclusion of the mounting operation. Finally, a global view of the building after the completion of the works is shown in Fig. (19). The computed cost of the structural works, equal to $135 \mathrm{Eu}-$ $\operatorname{ros} / \mathrm{m}^{2}$, is nearly coincident with the cost estimated for the Bisignano building. The resulting saving as compared to the cost of traditional retrofit solutions is thus totally confirmed.

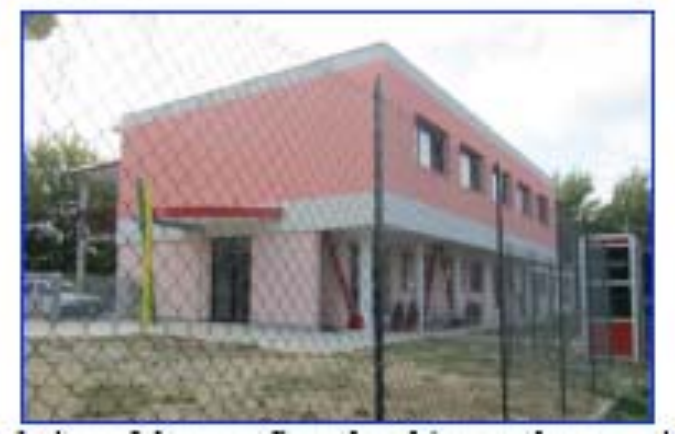

Fig. (19). View of the building after the completion of the retrofit and architectural renovation works.

\section{CONCLUSIONS}

The DB-based seismic retrofits designed for the two R/C school buildings examined in this paper allowed reaching target performance objectives with small-sized dampers and bracings. This guarantees lower costs, as well as limited architectural impact and a renewed look of the buildings, as compared to the adoption of traditional intrusive seismic design strategies.

Starting from a poor seismic performance of the original structures in terms of interstory drifts for all reference seis- 
mic levels, as well as of safety conditions in the existing frame members for BDE and MCE, the incorporation of the protective system helps meeting the strict performance requirements postulated for these retrofit designs. These requirements are synthesized by drift ratios not exceeding $0.33 \%$ (FDE), $0.5 \%$ (SDE), $1.5 \%$ (BDE), and $2 \%$ (MCE) in the weakest direction of the buildings, a general elastic response for BDE, and slight plasticizations to few members for MCE. As a consequence, strengthening of beams and columns, or of foundations, was limited to a very small number of members originally undersized to gravitational loads, while they would involve most of members in the case of conventional rehabilitation designs.

The equivalent linear viscous damping ratios computed from the energy responses is greater than $30 \%$, at the MCE level of seismic action, for both buildings. In addition to the above-mentioned drastic cut in interstory drifts, as well as in rotations and stresses of frame members, this high damping capacity of the DB system also produces a greater than 50\% reduction of the total base shear of the structure, when passing from original to retrofitted conditions.

The very quick installation times of the protective system, checked in its first actual application to the Borgo San Lorenzo structure, guarantee a short interruption in the use of the buildings, which represents another fundamental requirement in the seismic rehabilitation and architectural renovation of public edifices.

Based on these findings, the two case studies confirm the potential of the DB system as a retrofit strategy for the stock of $\mathrm{R} / \mathrm{C}$ buildings, either pre-normative or designed with earlier Seismic Standards editions, with similar characteristics to the buildings considered herein.

\section{CONFLICT OF INTEREST}

The authors confirm that this article content has no conflicts of interest.

\section{ACKNOWLEDGEMENTS}

The study reported in this paper was financed by the Italian Department of Civil Protection within the ReLUIS-DPC Project 2010/2013. The authors gratefully acknowledge this financial support.

\section{REFERENCES}

[1] M. C. Constantinou, T. T. Soong, and G. F. Dargush, Passive energy dissipation systems for structural design and retrofit, Monograph series No. 1, MCEER, Buffalo, NY, 1998.

[2] R. D. Hanson, and T. T. Soong, Seismic design with supplemental energy dissipation devices, Publication MNO-8, EERI-Earthquake Engineering Research Institute, Oakland, CA, 2001.

[3] S. Brzev, and F. Naeim, Overview of advanced technologies, World Housing Encyclopedia, Summary Publication, EERI, Oakland, CA, 2004.

[4] C. Christopoulos, and A. Filiatrault, Principles of passive supplemental damping and seismic isolation, IUSS Press, Pavia, Italy, 2006.

[5] M. C. Constantinou, and M. D. Symans, "Experimental study of seismic response of buildings with supplemental fluid dampers", Journal of the Structural Design of Tall Buildings, vol. 2, pp. 93132, 1993

[6] G. Pekcan, J. B. Mander, and S.S. Chen, "The seismic response of a 1:3 scale model R.C. structure with elastomeric spring dampers", Earthquake Spectra, vol. 11, no. 2, pp. 249-267, 1995.
S. Sorace, and G. Terenzi, "Iterative design procedure of fluid viscous devices included in braced frames", Proceedings of EURODYN '99 - $4^{\text {th }}$ European Conference on Structural Dynamics, Prague, Czech Republic, pp. 169-174, 1999.

[8] W. H. Lin, and A. K. Chopra, "Asymmetric one-storey elastic systems with non-linear viscous and viscoelastic dampers: simplified analysis and supplemental damping system design", Earthquake Engineering and Structural Dynamics, vol. 32, no. 4, pp. 579-596, 2003.

[9] S. Sorace, and G. Terenzi, "Large-scale experimental validation of a design procedure for damped braced steel structures", Proceedings of STESSA $2003-4^{\text {th }}$ International Conference on the Behaviour of Steel Structures in Seismic Areas, Naples, Italy, pp. 657662, 2003.

[10] F. J. Molina, S. Sorace, G. Terenzi, G. Magonette, and B. Viaccoz, "Seismic tests on reinforced concrete and steel frames retrofitted with dissipative braces", Earthquake Engineering and Structural Dynamics, vol. 33, no. 12, pp. 1373-1394, 2004.

[11] L. Guerreiro, A. Craveiro, and M. Branco, "The use of passive seismic protection in structural rehabilitation", Progress in Structural Engineering and Materials, vol. 8, no. 4, pp. 121-132, 2006.

[12] F. Mazza, and A. Vulcano, "Control of the along-wind response of steel framed buildings by using viscoelastic or friction dampers", Wind \& Structures, vol. 10, no. 3, pp. 233-247, 2007.

[13] S. Sorace, and G. Terenzi, "Seismic Protection of Frame Structures by Fluid Viscous Damped Braces", Journal of Structural Engineering, ASCE, vol. 134, no. 1, pp. 45-55, 2008.

[14] S. Sorace, and G. Terenzi, "Fluid viscous damped-based seismic retrofit strategies of steel structures: General concepts and design applications", Advanced Steel Construction, vol. 5, no. 3, pp. 322339, 2009.

[15] F. Mazza, and A. Vulcano, "Control of the earthquake and wind dynamic response of steel-framed buildings by using additional braces and/or viscoelastic dampers", Earthquake Engineering \& Structural Dynamics, vol. 40, pp. 155-174, 2011.

[16] R. Ozcelik, U. Akpinar, and B. Binici, "Seismic retrofit of deficient RC structures with internal steel frames", Advances in Structural Engineering, vol. 14, no. 6, pp. 1205-1222, 2011.

[17] R. Ozcelik, B. Binici, and O. Kurc, "Pseudo dynamic testing of an RC frame retrofitted with chevron braces", Journal of Earthquake Engineering, vol. 16, no. 4, pp. 515-539, 2012.

[18] F.C. Ponzo, A. Di Cesare, D. Nigro, A. Vulcano, F. Mazza, M. Dolce, and C. Moroni, "JET-PACS project: dynamic experimental tests and numerical results obtained for a steel frame equipped with hysteretic damped chevron braces", Journal of Earthquake Engineering, vol. 16, pp. 662-685, 2012.

[19] S. Sorace, and G. Terenzi, "The damped cable system for seismic protection of frame structures - Part I: General concepts, testing and modelling", Earthquake Engineering and Structural Dynamics, vol. 41, no. 5, pp. 915-928, 2012.

[20] S. Sorace, and G. Terenzi, "The damped cable system for seismic protection of frame structures - Part II: design and application", Earthquake Engineering and Structural Dynamics, vol. 41, no. 5, pp. 929-947, 2012.

[21] S. Sorace, G. Terenzi, and G. Bertino, "Viscous dissipative, ductility-based and elastic bracing design solutions for an indoor sports steel building", Advanced Steel Construction, vol. 8, no. 3, pp. 295316, 2012.

[22] S. Sorace, and G. Terenzi, and F. Fadi, "Shaking table and numerical seismic performance evaluation of a fluid viscous-dissipative bracing system", Earthquake Spectra, vol. 28, no. 4, 2012.

[23] S. Sorace, and G. Terenzi, "Non-linear dynamic modelling and design procedure of FV spring-dampers for base isolation", Engineering Structures, vol. 23, no. 12, pp. 1556-1567, 2001.

[24] S. Sorace, and G. Terenzi, "Non-linear dynamic design procedure of FV spring-dampers for base isolation - Frame building applications", Engineering Structures, vol. 23, no. 12, pp. 1568-1576, 2001.

[25] S. Sorace, G. Terenzi, G. Magonette, and F. J. Molina, "Experimental investigation on a base isolation system incorporating steelTeflon sliders and pressurized fluid viscous spring dampers", Earthquake Engineering and Structural Dynamics, vol. 34, no. 2, pp. 225-242, 2008.

[26] S. Sorace, and G., Terenzi, "Analysis and demonstrative application of a base isolation/supplemental damping technology", Earth quake Spectra, vol. 24, no. 3, pp. 775-793, 2008. 
[27] Computers \& Structures Inc., SAP2000NL. Structural analysis programs - Theoretical and users manual, Release no. 14.09, Berkeley, CA, 2012.

[28] Italian Council of Public Works, Technical Standards on Constructions [in Italian], Rome, Italy, 2008.

[29] T. Takeda, M. A. Sozen, and N. N. Nielsen, "Reinforced concrete response to simulated earthquakes," Journal of the Structural Division, ASCE, vol. 96, pp. 2557-2573, 1970.
[30] ASCE/SEI 41-06, Seismic rehabilitation of existing buildings, American Society of Civil Engineers - Structural Engineering Institute, Reston, VA, 2006.

[31] Jarret SL, "Shock-control Technologies", Available from: http://www.introini.info, 2012.

Received: August 23, 2012

Revised: October 08, 2012

Accepted: October 15, 2012

(c) Sorace and Terenzi.; Licensee Bentham Open.

This is an open access article licensed under the terms of the Creative Commons Attribution Non-Commercial License (http://creativecommons.org/licenses/by-nc/3.0/) which permits unrestricted, non-commercial use, distribution and reproduction in any medium, provided the work is properly cited. 